\title{
Dynamics of sense-making and development of the narrative in the clinical exchange
}

\author{
Alessandro Gennaro ${ }^{1}$, Miguel Gonçalves ${ }^{2}$, Inês Mendes², \\ António Ribeiro ${ }^{2}$, Sergio Salvatore ${ }^{1}$
}

\begin{abstract}
The present work is aimed at exploring the relationship between the dynamics of sense-making carried out by the clinical exchange and the content of the patient's narrative. To this end the relationship between the formal and functional mapping of a psychotherapy carried out by the Discourse Flow Analysis (DFA) and the analysis of the patient's narrative provided by the Innovative Moment Coding System (IMCS) have been compared. The comparison concerns a 15-session good outcome EmotionFocused Therapy (Lisa's case). Findings highlight the association between the formal and functional characteristics of the clinical dialogue and the content of the narrative. More in particular, an association between the U-shape trajectory of the super-ordered meaning depicted by DFA and the evolution of the innovative content of the narrative enucleated by the IMCS were found.
\end{abstract}

\section{Key words}

Process research; meaning making; DFA; IMCS

1Università del Salento, Italy
2Universidade do Minho, Portugal

Corrispondence: Alessandro Gennaro alessandro.gennaro@unisalento.it 


\section{Introduction}

Several clinical approaches - psychodynamic (Hoffman, 1998; Storolow, 1994), cognitive (Dimaggio \& Semerari, 2004), humanistic (Hermans \& Hermans-Jansen, 1995) and narrative (Santos, Gonçalves, Matos, \& Salvatore, 2009) - share a meta-theoretical perspective seeing the psychotherapy as an intersubjective dynamics of sense-making aimed at changing patient's symbolic (affective and/or cognitive) modality of interpreting his/her experience (Gennaro, Al-Radaideh, Gelo, Manzo, Nitti, Auletta \& Salvatore, 2010), or anyway able to open toward new, innovative way of thinking and feeling - therefore of interpreting the experience and acting own life (Santos \& Gonçalves, 2009). Viewing psychotherapy process under this light implies conceiving clinical exchange as a "transformative dialog" (Gergen, 1999, p. 250), where new meanings are elaborated, new categories are developed, and one's presuppositions (Chambers \& Bickhard, 2007) are transformed within and thanks to the interpersonal context. This means that the clinical valence of patient-therapist relationship does not consist of pushing the patient to change the content of his/her representations about self and world (e.g., the way of seeing relations with others, judgments on events and acts, and so on); rather psychotherapy has to be seen in a broader way, as an intersubjective attempt aimed at opening new semiotic configurations, that is new paths of sense-making able to offer patients an innovative way to organize their experience (Salvatore, Gelo, Gennaro, Manzo, \& AlRadaideh, 2010). In other words, the clinical exchange is a dialectic encounter between the patient's and the therapist's way of interpreting the world, producing (for both participants) semiotic novelty working as a lever for patient's change.

As suggested by Lauro-Grotto, Salvatore, Gennaro and Gelo (2009) sense-making could be depicted as a dynamic process, that is a process depending on time. Different perspectives of philosophical, semiotic and 
sociologic thought, as well as a number of psychological models (Valsiner \& Van der Veer, 2000; Gergen, 1999; Nightgale \& Comby, 1999; Cole, 1996; Edward \& Potter, 1992) have argued for the classical additional and static idea of communication as the transmission of semantic contents, underlining the pragmatic (Austin,1962) and pathic (Freda, 2008) valence of meaning as well as its contingence to the discursive circumstances (Salvatore, Tebaldi, \& Poti, 2006/2009; Salvatore et al., 2010). Meaning deals with the exchange of signs (i.e. words, utterances, behaviours and so on). On the other hand, signs are part of a whole dynamic context concurring to sustain and shape the flow of the communication. Each sign is mobilized by the participants of the dialogue as an answer to the previous signs, and as an anticipation of the future ones (Linell, 2009). Thus, sense-making is inherently a time-dependent process, where meaning is not laid within the signs; rather it is an emerging property of the exchange, raising from the combination of the signs, that is from the act of saying something in a certain way, to someone, in a specific space and time, in the light of a specific and socially defined relation between speakers (Harre \& Gillet, 1994, Wittgenstein, 1953; Greenberg \& Pinsoff, 1986). In other words, the meaning of the signs depends on the way they are used (Wittgenstein, 1953) - namely, how they are combined with other signs within the intersubjective circumstances of the discourse.

\section{A dynamic and contextual look at psychotherapy process}

As sense-making, the psychotherapy has to be conceived of as a dynamic phenomenon too, that is a process depending on the time and concerning the global form and organization of the intersubjective field of communication between therapist and patient (Salvatore et al., 2009). Which means that the clinical exchange is carried out not only by means of what is said, and not only by how it is said, but also by means of when what said is said - that is, before and after what (Salvatore et 
al., 2009; Lauro-Grotto et al., 2009). To exemplify let us consider the following sequences characterizing a hypothetical patient's sentence:

Patient 1: When I lose through gamble I got very angry and therefore I desired to be helped by the therapist.

Patient 2: When I desired to be helped by the therapist I got very angry and therefore I lose through gambling

As one can see, even if the contents are the same for both sequences, the difference in the sequence of the signs (indeed a matter of time) makes a difference in the meaning: while the first sentence expresses the patient's need of therapist support because of his gamble loosing, the second sentence expresses the gambling as a form of "acting out" in front of patient's desire of being supported. It is worth noting that such view is not new in the clinical field. The psychoanalytic hermeneutic tenet of the free association is indeed based on the criterion of temporal contiguity between signs, that is on the assumption that the meanings depend on the way signs combine with each other through time.

\section{A method for grasping the dynamicity of the psychotherapy process}

The acknowledgment of the dynamicity of the clinical process triggers a commitment for innovative methodology (Greenberg, 1994; Salvatore, Gennaro, Grassi, Manzo, Melgiovanni, Mossi, Olive, \& Serio, 2007; Valsiner et al., 2009). As matter of fact, despite of some pioneering attempts (Kowalik, Schiepek, Kumpf, Roberts, \& Elbert, 1997; Schiepek, Kowalik, Schiitz, Kohler, Richter, Strunk, Miihlnickel, \& Elbert, 1997; Stiles, 2006; Tschacher, Schiepek, \& Brunner, 1992; Tschacher, Baur, $\&$ Grawe, 2000), current methods are still based on the idea of recomposing the process in terms of the linear addition of single timediscrete events (Elliott \& Anderson, 1994; Russell, 1994; Stiles, 2006). Recently a new method of analysis - the Discourse Flow Analysis (DFA) - have proposed in order to address this methodological issue (Salvatore et al., 2007; Salvatore et al., 2010; Gennaro et al., 2010; Nitti, Ciavolino, Salvatore, \& Gennaro, 2010). DFA is aimed at mapping 
the dynamics of sense-making sustaining the psychotherapy. To this end it focuses the formal and functional characteristics of the dialogue between the therapist and the patient (i.e., the degree of connectivity among the meanings), not considering the semantic contents exchanged through that dialogue.

\section{Aim of the study}

As far the studies that have applied the DFA have been dealt with its construct validity - that is on its consistency with the theoretical model (the Two Stage Semiotic Model, see below) on which DFA is grounded. However, these studies have left apart the relationship between the formal and functional characteristics of the clinical dialogue mapped by the DFA and the content of the narrative. Needless to say that understanding this relationship is a central topic for the developing of the method. As matter of fact, even if it is conceivable and even desirable (Salvatore et al., 2010) that the modelling of the psychotherapy could be a matter of not observable theoretical constructs rather than of empirical concepts directly derived from the experience, nevertheless the clinical meaningfulness of the theoretical constructs depends on the fact that they are however connected to the clinical experience. Only at this condition the conceptual model is able to help the interpretation of the clinical experience. The present work intends to address this lack. It investigates the relationship between the formal and functional mapping of a psychotherapy case and the content of the patient's narrative, as provided by a method focused on such level of analysis - the Innovative Moments Coding System (IMCS; Gonçalves, Matos, \& Santos, 2008). The main aim is to chart out which kind of movements at level of narrative content corresponds to the dynamics of sensemaking carried out by the clinical dialogue as depicted by the DFA. 


\section{The Discourse Flow Analysis}

The theoretical framework: the Two Stage Semiotic Model

DFA is based on a general model of the psychotherapy, holding the dynamic and dialogical nature of the clinical exchange: the Two Stage Semiotic Model (TSSM). The TSSM is based on three main assumptions (Salvatore et al., 2010; Gennaro et al., 2010; Nitti et al., 2010): the Two stage articulations; the Non-linearity, and the Quasi periodicity microdynamics of the psychotherapy process.

Two stage articulation. The TSSM claims that a clinical efficacious therapy course highlights two periods: the first stage reflects a deconstructive phase, (Hayes \& Strauss, 1998; Kossmann \& Bullrich, 1997; Mahoney \& Marquis, 2002) when the clinical exchange is mainly aimed at constraining patient's system of assumptions (concepts of self and others, affective schemata, meta-cognitive modalities, relational and attachment strategies, unconscious plans, etc.) working as superordered meanings regulating the interpretation of experience (Teasdale $\&$ Barnard, 1993). The weakening of the patient's critical super-ordered meaning (Salvatore \& Valsiner, 2006; Samoilov \& Goldfried, 2000) paves the way for the second, constructive phase when the therapeutic dialogue allows the elaboration of innovative super-ordered meanings, replacing the previous ones in regulating the patient's way of interpreting the experience. It is worth noting that, as concerns the patient's super-ordered meanings, the two stages are different both from a quantitative and a qualitative point of view. From a quantitative point of view, the model holds that the incidence of the super-ordered meanings decreases in the first stage while increases in the second. From a qualitative point of view, the model assumes that the clinical value (i.e., the function played by the content of the node within the clinical exchange) of the super-ordered meaning changes as well. In the 
first period of a psychotherapy one can assume that the super-ordered meanings reflects the dysfunctional way of thinking and feeling that the person has before to ask for a psychotherapy. As matter of fact, given that generally one demands a psychotherapy in order to address problems and critical issues in her/his life, and given that it is assumable that those problems and critical issues are associated, even caused, by this way of thinking and feeling, one is led to conclude that the patient enters psychotherapy with dysfunctional super-order meanings, that is meanings associated with the conditions leading a person to become a patient. On the contrary, according to the TSSM assumption, the super-order meanings of the second stage of good outcome psychotherapy should be associated with the positive results of the clinical work, therefore, broadly speaking, functional.

Non-linearity. The second assumption of the TSSM maintains that the therapeutic process draws not linear trajectories through time. It follows from the previous assumption. Since clinical relationship performs different functions in the therapy accordingly to the two stages (that is a deconstructive and a constructive function), different functional organization or mode of working of the clinical process have to be associated with this articulation. In other terms, the de-constructive and the constructive stages are expected to be characterized by different patterns of relationships among those features of the therapeutic dialog, which contribute to meaning-making.

Quasi periodicity of the micro-dynamics. The third assumption assumes a heartbeat-like quasi-periodic mechanism of working, in which moments of "basic" sense-making, during which the active system of assumptions works, are interrupted by circumscribed moments of recombination of the connections between meanings, which could be seen as an "irruption" of semiotic variability. The new pattern of connections produced by this irrupting moment afterwards becomes more and more firmly established, implementing a further phase of 
basic sense-making that will be interrupted by another irruption moment, and so on.

The rationale of the method. DFA assumes that sense-making depends on the associations for temporal adjacency between meanings - that is, on the way meanings combine each other throughout the discourse flow (therefore through the time). Accordingly, DFA maps the psychotherapeutic dialogue in terms of associations for adjacency between semantic contents (i.e., the fact that one meaning comes just after another) occurring within the clinical exchange. DFA does it by referring to the notion of "Discourse Network." A Discourse Network is a web with each node representing one of the units of meaning (henceforth: semantic content) that is active in the dialogue between therapist and patient. Any line between two nodes represents the temporal association between the corresponding semantic contents; the thickness of the line represents the strength of the association (that is, the probability that a certain semantic content will be followed immediately by the other). For instance, referring to Figure 1, the

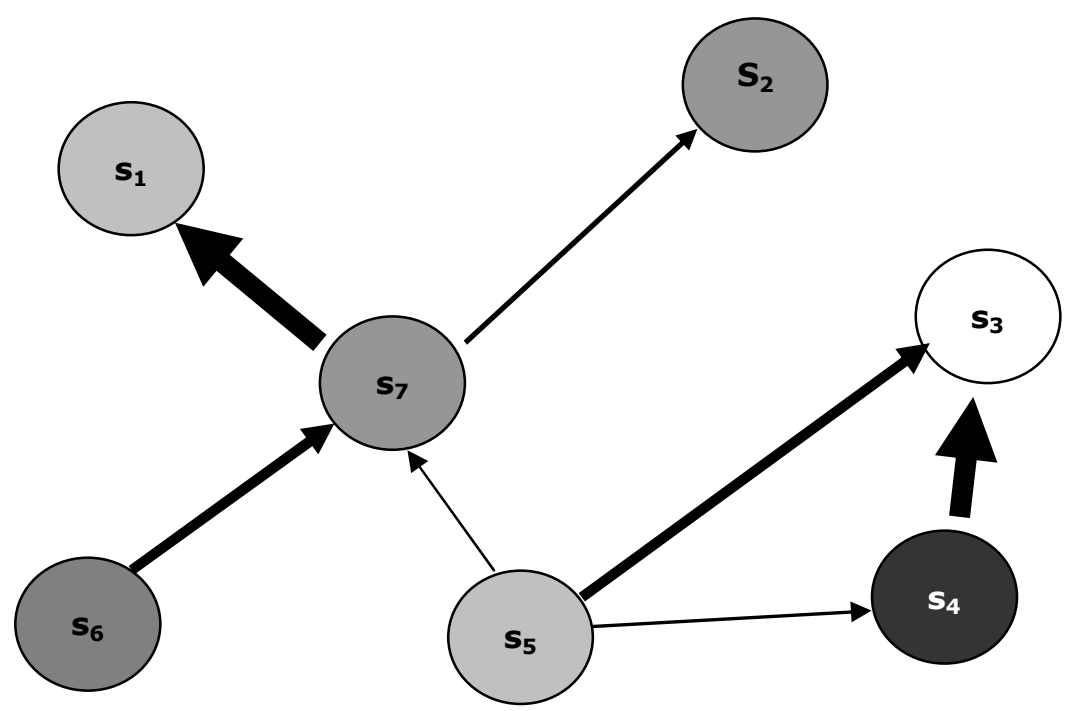

Figure 1. An example of nodes network: each node $S(n)$ represents a semantic content. The thickness of the arrows that reflect directional linkage represent the strength of the temporal association between contents. 
Discursive Network is described by the semantic content (S5) followed mostly by the semantic content (S3) and in some cases by (S4) and (S7). In turn, this last semantic content precedes (S1) mostly and in some cases (S2); and so on.

\section{Procedure of analysis and indexes}

DFA is applied to the verbatim transcript of the dialogue between therapist and patient throughout three different steps that will be briefly described.

The first step consists of a computer-aided content analysis, which identifies and categorizes the semantic contents active in the whole verbatim transcription of patient-therapist dialogue (DFA refer only to verbal content, paralinguistic or extra verbal data are not taken into consideration). This passage is performed through various sub-steps:

1. the transcript is divided into units of analysis called Elementary Context Units (ECU) through the software T-LAB (Lancia, 2002). An ECU starts with the characters just subsequent to the last character of the previous ECU and ends with the first punctuation mark ("." or “!” or "?”) after the 250th character; at any rate the length must not be more than 500 characters.

2. In order to reduce the lexical variability due to syntax, a procedure of lemmatization classifies each word according to its headword (for example, word forms like "child," and "children" are transformed into its lemma "CHILD"). This operation leads to a list of the lemmas present in the transcript.

3. A matrix having the ECUs as rows and the lemmas as columns is drawn where in the generic cell $x_{i j}$ the value " 1 " represent the presence of the $j^{\text {th }}$ lemma in the $i^{\text {th }}$ ECU, "O" otherwise. The obtained matrix represents a digital model of the text, in its distribution of 
presence/absence of the lemmas in the ECUs composing the text.

4. A Multiple Correspondence Analysis (MCA; Benzécri, 1973) is applied to the digital matrix representing the text obtained as output of the previous sub-step. Each factor enucleated by the MCA describes the joint behavior of groups of lemmas and can be interpreted as a significant semantic dimension expressed by the conversation.

5. A Cluster Analysis (CA; Bolasco, 1999) is then performed, adopting the factors resulting from the MCA as criterion of classification. According to its composition, each ECU is assigned to the cluster with which it has the highest association. Therefore, each cluster will represent a subset of words tending to occur in the same sentences. Therefore, each cluster can be understood as a unit of meaning that is a thematic nucleon (or semantic content, or node), made up of a set of words whose aggregation reflects the "isotopy" (i.e., "iso" = same; "topos" = place) of semantic traits (Lancia, 2004; on this topic see also Salvatore, Gennaro, Auletta, Al-Radaideh, Aloia, Masiello, Montreforte, Tonti, Manzo, \& Gelo, 2010).

6. Each ECU is indexed according to the cluster it belongs to. Therefore, the output of DFA's first step (sub-steps 1-6) is the transformation of the transcript into a sequence of thematic contents, each of them representing the semantic content of an ECU.

The second step of the DFA method is aimed at building a model of the text in terms of Discursive Network where nodes are represented by the semantic content (i.e., the Clusters) and the connections among them represent the strength of their association for adjacency. The strength of the association among the cluster is calculated using a procedure of Markov's analysis of sequence (Bakeman \& Gottman, 1997). This procedure calculates each semantic content's probability of coming straight after every thematic content (including itself, given that a semantic content can follow itself too). 
The third step of the DFA method is aimed at analyzing the formal and functional characteristics of the Discourse Network as produced by the previous step, insofar as they are considered indicative of relevant aspects and qualities of the dynamics of sense-making. This passage is carried out by means of some indexes, which gives a synthetic description of the Discursive Network's functioning. The main indexes are the following (for further detail, see also Salvatore et al., 2010; Gennaro et al., 2010; Nitti et al., 2010; Salvatore et al., 2007):

Super-Ordered Nodes (SN). This index quantifies the incidence of the nodes carrying out a function of super-ordered meaning regulating the meaning-making process. Thus it measures the incidence of the superordered meanings the TSSM's first assumption (i.e., the Two stage articulation) is concerned with DFA assumes the high frequency of occurrence of a node (i.e., the number of the times the semantic content occurs in the unit of text under analysis in other terms) and its high associability with the other nodes as the markers of this super-ordered regulative function. Super Order Nodes are calculated as the percentage of nodes of the network having both high frequency, calculated as more than a 1.5 ratio between token (occurrences of a given thematic content) and type (kinds of thematic content), and high associability, calculated as having outgoing and/or incoming connections with more than 33\% of the nodes in the network.

According to the TSSM's first assumption, one is expect to find a Ushape trend of this index through the psychotherapy course, with a first part of the psychotherapy characterized by a decreasing trajectory followed by a second part where the SN increases.

Activity (A). It is the index providing a quantitative description of the micro-dynamics of the sense-making the TSSM's third assumption (i.e. the Quasi-periodic micro-dynamics) is concerned with. It depicts the 
discourse's capability of broadening (or constraining) the paths of sense-making, by enriching or restricting the possibilities of combination among the semantic content. It is calculated in terms of the nodes ratio between the outgoing and incoming connections. A node with more outgoing connection than incoming generates meaning variability, because its activation entails an enlargement of the spectrum of semantic content respect on the previous node. The opposite occurs in the case of nodes having more incoming connections than outcoming. This kind of nodes represents semantic content that "absorbs" meaning variability.

According to the TSSM's third assumption, one is expect to find a heartbeat-like quasi-periodic of this index through the psychotherapy course.

Connectivity. It is a measure the network's density of associations, that is of the relative amount of connections among the semantic content. It is calculated as the ratio between the active connections present in the network (as identified through the Markovian analysis) and the network's maximum theoretical amount of connections.

Heterogeneity. It depicts how the connections are distributed among the nodes. It is calculated as the standard deviation of the distribution of the amount of connections starting from and arriving at every semantic node.

The construct validity of DFA

Several case studies have investigated the DFA's construct validity, in terms of the consistency between the operative representation of the psychotherapy process provided by the method and the TSSM's assumptions. Salvatore and colleagues (in press) have applied DFA to a good outcome 15 sessions Emotion Focused psychotherapy (the same 
case adopted in the present work) and have highlighted the presence of the expected U-shape trend of the SN, indicative of the two stage articulation. Moreover the same study, in accordance with the TSSM's second assumption (non-linearity), has highlighted the different way of functioning of the clinical dialogue in the two periods. Gennaro and collegues (in press) have applied the DFA to a good outcome 124 sessions Metacognitive Interpersonal psychotherapy (Dimaggio, Semerari, Carcione, Nicolò, \& Procacci, 2007) highlighting how results are consistent with the three TSSM assumptions. Finally, Nitti et al., (2010) applied the DFA to 43 psychotherapy sessions randomly sampled from the total of 79 sessions of a good outcome psychodynamic psychotherapy. They have found that the indexes measuring the structural and dynamics characteristics of the Discourse Networks are able to discriminate between two periods of the psychotherapy as independently defined accordingly to the TSSM criterion of the two stages articulation.

Taken as a whole, these studies provide evidence supporting the TSSM's assumptions, as well as the DFA's validity as a method providing a meaningful map of the psychotherapy process in terms of its formal and functional characteristics. Moreover, the variety of therapy and setting involved in the studies legitimates to think that the method could be considered as independent on the type of setting (brief versus long therapy) as well as on the clinical orientation.

\section{Method}

Data

The present study concerns the whole textual corpus obtained from the verbatim transcript of a 15-session good outcome psychotherapy taken from the York Psychotherapy Depression Project. The data on which it is based are obtained by two previous studies (Gonçalves et al., 
2009; Salvatore et al., 2010) which have already independently applied the two methods here compared (respectively IMCS and DFA) on the case. In accordance with its dialogical theoretical framework, DFA were applied to the whole transcript of the dialogue between therapist and patient. IMCS were applied only to the part of the text produced by the patient.

The patient (Lisa) was a young, married woman in her late $20_{\text {s }}$ who received an Emotion-Focused Therapy for depression (see Greenberg \& Watson, 1998; Goldman, Greenberg, \& Angus, 2006). The York Psychotherapy Depression Project envisaged the recruitment of participants by advertisement, an initial session of assessment based on the use of the full multi-axial version of the SCID III-R, and a set of outcome measures applied before treatment, at mid-treatment (session 8), at post-treatment, and at 6- and 18-month follow-ups: the Beck Depression, Inventory (Beck, Ward, Mendelson, Mock, \& Erbaugh, 1961), the Rosenberg Self-Esteem Scale (Rosenberg, 1965), the Inventory for Interpersonal Problems (Horowitz, Rosenberg, Baer, Ureno, \& Villasenor, 1988), and the Symptom Checklist-90-R (Derogatis, Rickels, \& Roch, 1976). Lisa made significant gains on all measures, maintaining and even improving, particularly in terms of self-esteem at the follow-up assessments (for details see Angus, Goldman, \& Mergenthaler, 2008). Lisa also completed a process measure, the Working Alliance Inventory Short-Form (Horvath \& Greenberg, 1989), after session 4, 7 and 15. The case of Lisa has been recently analyzed according to different theories and methodologies (see Angus, Goldman, \& Mergenthaler, 2008). 
The Innovative Moments Coding System (IMCS) has been adopted in order to analyze the content of patient's narrative. This choice has been made according to the following criteria:

a) IMCS shares a semiotic and dynamic conception of the psychotherapy process with the DFA (Matos et al., 2009; Gonçalves, Ribeiro, Matos, Santos \& Mendes, 2010, Santos, Gonçalves, Matos \& Salvatore, 2010).

b) IMCS is specifically focused on the novelty produced within the narrative, that is the semantic content potential marking a clinically relevant development. This characteristic is particular relevant for our scope of analyzing the clinical meaningfulness of the formal and functional characteristics of the dialogue measured by the DFA.

IMCS is a method applied to the verbatim transcript of the patient's narrative within the session. It is aimed at analyzing the way the narrative of the patient conveys and reflects the clinical change. IMCS is based on a narratological conception of the psychotherapy. According to this standpoint, the therapeutic change depends on the promotion of the patient's capability of elaborating alternative accounts of the events (Freedman \& Combs, 1996; White, 2007). This elaboration leads to substitute/develop the dysfunctional narratives grounding the patient's problems, allowing the client to construct innovative ways of interpreting the self and the relationship with the world. In its turn, the construction of this innovative ways leads the client to feel, think, and act differently from the past modalities framed by the problematic story. In sum, similarly to the DFA, the IMCS assumes a way of viewing the psychotherapy as a semiotic process at producing novelty in sensemaking: new meanings that the patient can deploy in order to re-shape her/his life. Differently from the DFA, however, the IMCS focuses the content level of the sense-making.

The IMCS is aimed at identifying the narrative (namely, the Innovative Moments) producing a change - or however a movement of 
dialectization - of the problematic dominant narrative the patient is constrained with. The method considers 5 types of Innovative Moments (i-momentos) (for details see Gonçalves, Matos, \& Santos, 2009; Goncalves, 2010):

1. Action, that is an i-moment referred to specific actions that are not predicted by the problematic story.

2. Reflection, that is an i-moment in which the patient thinks differently than what one could expect from the problematic story, or when he/she understands something new, that contradicts the problematic story.

3. Protest i-moment could be an action or a thought reflecting a reaction of resistance against the problematic narrative and its detrimental effects, and which leads the person to protest against the problematic narrative and/or the assumptions that support it. Protest implies both aspects of resistance and re-assessment of the client's position in relation to the problem.

4. Re-conceptualization is an i-moment that involves two components: the contrast between the past self and the present self, and the description of the processes that allowed the self's transformation from the past to the present. This i-moment implies the activation of a meta-level, enabling the patient to see the difference between the old plot and the (anticipated) new one, as well as to construct the development of the new story.

5. Performing change is an i-moment revealing new experiences, projects, or activities at personal, professional, and relational level which were impossible before, given the constraints of the dominant narrative - marking the consequences of the occurred change.

The IMCS measures the relevance of the i-moments in terms of duration, which is the amount of time (in percentage) that each imoment occupies in the whole session. Therefore, the application of the IMCS allows calculating the duration of each type of i-moments as well 
as the total duration of the i-moments respect of the rest of the patient's discourse. This can be calculated for the whole therapy as well as for more specific unit of analysis (sessions or block of sessions).

It is worth noting that the $5 \mathrm{i}$-moments can be grouped in two more general categories. Action, Reflection and Protest are i-moments that represent a rupture in respect to the dominant narrative. Reconceptualization and Performing change can be interpreted more as the marked of an elaborative process producing a consolidation of the new perspectives opened by the weakening of the dominant narrative. Consistently with this interpretation of the clinical significance of the imoments, Action, Reflection and Protest characterize the first part of the therapy, while the Re-conceptualization and the Performing change are typical of the final part of the clinical course of good outcome psychotherapy (Matos, Santos, Gonçalves, \& Martins, 2009). On the basis of these findings, authors interpret Re-conceptualization and Performing change as the final step of the process of elaboration of innovative sense-making in the psychotherapy. The following analysis adopt these two groups of i-moments as variables. In other terms, we consider the aggregate duration of Action, Reflection and Protest as the index of the "reactive" innovation the patient introduces and the aggregate duration of Re-conceptualization and New Experience as the index of the narrative's innovation reflecting an "elaborative" semiotic activity of the patient.

\section{Procedure and data analysis}

The study analyzes the relationship between the SN index elaborated by the DFA and the aggregate duration of the reactive i-moments (Action, Reflection and Protest) and the elaborative i-moments (Reconceptualization and Performing change). The aggregate duration of the reactive i-moments is given by the sum of the duration of the Action, Reflection and Protest. The aggregate duration of the elaborative 
i-moments consists of the sum of the Re-conceptualization and Performing change.

The analysis of the relationship among these three variables has been carried out adopting the session as unit of analysis. This means that the study is based on a data matrix made of 15 cases (the 15 sessions), with every case characterized by three values, one for each of the three indexes (i.e., SN, duration of the reactive i-moments; duration of the elaborative i-moments). This choice obviously reduces the potency of the statistical analysis. Nevertheless it is the only possible, given that the DFA assumes the session as the minimal unit of analysis.

We adopted the Spearman's Rho for measuring the degree of association between the SN and the two indexes derived by the IMCS: a non-parametric test in consideration of the assumed not independence of the cases has been chosen (Borckardt, Mash, Murphy, Moore, Shaw, \& O’Neil, 2007).

In accordance with the TSSM (in particular the assumption of two stage articulation and non-linearity) the analysis of the association between the indexes were performed separately for two blocks of contiguous sessions, supposed corresponding to the two stages conceptualized by TSSM. To this end we applied the criterion provided by the DFA - and already applied to this case by Salvatore and colleagues (in press) - that assumes the session having the minimal peak of the SN as cut off (obviously this criterion is sensate only in presence of the assumed U-shape trend of the SN). SN has been found equally low in sessions 3, 10 and 14; we have chosen session 10 as cut off is the only one among these three sessions to be consistent with the $\mathrm{U}$ slope. Therefore, we chose the latter as the cut off point to split the 15-session psychotherapy into two stages. Following these results, the de-constructive stage goes from session 1 to 10 , and the constructive stage from session 11 to 15 . 


\section{Hypotheses}

Our study deal with the analysis of the clinical value of the superorder meanings, as conceptualized by the TSSM's first and second assumptions (Two stage articulation and Non-linearity), and operatively measured by the DFA index SN (Super-Ordered Nodes). More in particular, we focus the following points, that we present separately for the two stages of the psychotherapy.

First stage. TSSM claims that in the first stage of the good outcome psychotherapy, the decreasing of the SN depicts the progressive reduction of the incidence of the dysfunctional patient's system of assumption. And this process opens the room to the elaboration of innovative meanings. In accordance with this assumption we expect to find a negative association between the $\mathrm{SN}$ trend and the duration of the i-moments. More specifically, we hypothesise that the negative association with SN concerns only the reactive i-moments (i.e., Action, Reflection and Protest, see above). This is because, in accordance with their clinical meaning (see above), the emergence of the reactive imoments do not require specific elaborative competence in the patient, being more a matter of rupture/resistance against the dominant narrative (this is the reason for which these IMs are the first to emerge, then to be characteristics of the first phase of the therapy, see above). Therefore, one is led to conclude that the emergence and increasing of the duration of these group of i-moments is directly associated with the weakening of the power of the patient's system of assumption grounding the dominant narrative. On the contrary, we do not expect an association between the SN's trend and the elaborative i-moments. This is because the emergence of the elaborative i-moments entails a previous development of the patient competence to elaborate own narrative (not for chance it occurs late in the therapy). Therefore, the weakening of the patient's super-ordered meaning is not sufficient for the development of the duration of the elaborative i-moments - what 
needs are new super-ordered meanings grounding and nourishing the patient's commitment on innovative in own narrative.

Second stage. In accordance with the TSSM, in this stage the SN change in their clinical value, concerning new, functional super-ordered meanings, product of the psychotherapeutic work. As consequence of this, we expect to find a change in the association between SN and the i-moments. More in particular, we expect the following results. Firstly, we expect to find the raising of a positive association between the SN and the elaborative IMs. This is because, as above said, the development of the elaborative i-moments requires not only the weakening of the initial patient's assumptions, but also the elaboration of new, functional super-ordered meanings. Secondly, as consequence of that, we expect to find the same negative association between the SN and the reactive $\mathrm{i}$-moments. Yet the quantitative and qualitative content of this association is different respect on the first stage. In the second stage this negative association would reflect the fact that thanks to and alongside the unfolding of the clinical work the initial reactive modality of performing innovation in narrative tend to reduce their duration, being progressively developing in more sophisticate forms (i.e. the ones depicted by the elaborative i-moments). Grossly speaking, in the second stage the reactive $\mathrm{i}$-moments no more represents a progress of therapy (as in the first stage), rather having to be meant as a critical point (their presence in the late phase of the therapy is typical of negative outcome cases; see Matos et al., 2009). Consequently, the duration of the reactive $i$-moments has to be expected to be negatively associated with the SN trend, describing the positive development of the clinical work.

The expectations above defined can be summarized in terms of the following 3 operative hypotheses:

Hypothesis 1) In the first stage of the psychotherapy a negative correlation between $\mathrm{SN}$ and the summed duration of Action, Reflection 
and Protest (namely the reactive i-moments), with SN decreasing and duration increasing.

Hypothesis 2) In the second stage of the psychotherapy a positive correlation between SN and the summed duration of Reconceptualization and Performing change (namely the elaborative imoments).

Hypothesis 3) In the second stage of the psychotherapy a negative correlation between SN and the summed duration of Action, Reflection and Protest (namely the reactive i-moments), with $\mathrm{SN}$ increasing and duration decreasing.

\section{Results}

Figure 1 presents the trend of the SN through the sessions. This trend presents a course significantly close to a U-shape, with 11 out 15 sessions (sessions $1,2,4,5,6,8,9,10,11,14,15$ ) having a position that is consistent with a $U$ format (chi square highly significant: p. > .01). Sessions 3, 10 and 14 are the minimal peaks and sessions 1,12 and 15 the maximum peaks. Basing on the analysis of the confidence interval, Salvatore and colleagues (Salvatore et al., in press) have highlighted how the Super-Ordered Node values present a course significantly close to a U-shape at a significance level between $\alpha=5 \%$ and $\alpha=1 \%$. 


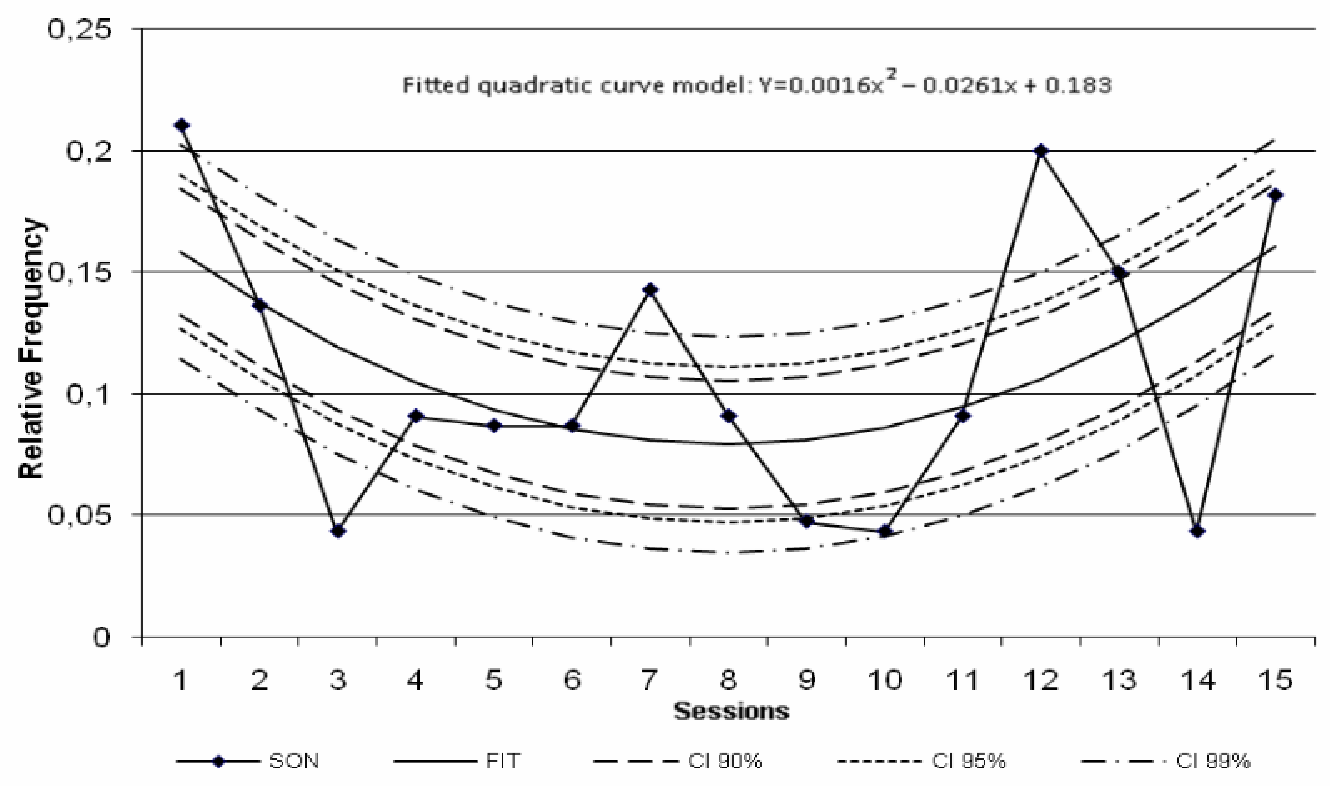

Figure 1. Fitted Quadratic curve (FIT) of Super-Ordered Nodes (SON) over the sessions with correspondent Confidence Intervals (CI), taken from Salvatore and colleagues (2010).

The Figure 2 shows the trend of the duration of the reactive imoments and elaborative i-moments. As already highlighted by Gonçalves and colleagues (in press), the duration of the reactive imoments increases in the first part of the therapy, getting the maximum peak in the session 8 , after which it decrease. This trend draws a U-inverse trajectory. The second order equation $\left(y=-0,378 \mathrm{x}^{2}+\right.$ $5,908 x+13)$ explains the $65 \%$ of the variance of this trajectory. The duration of the elaborative i-moments seems to have a different trend in the two stages. In the first stage (i.e., session 1-10 sessions) it is quite instable, alternating maximum and minimal peaks, while in the second stage shows a constantly increasing trajectory. 


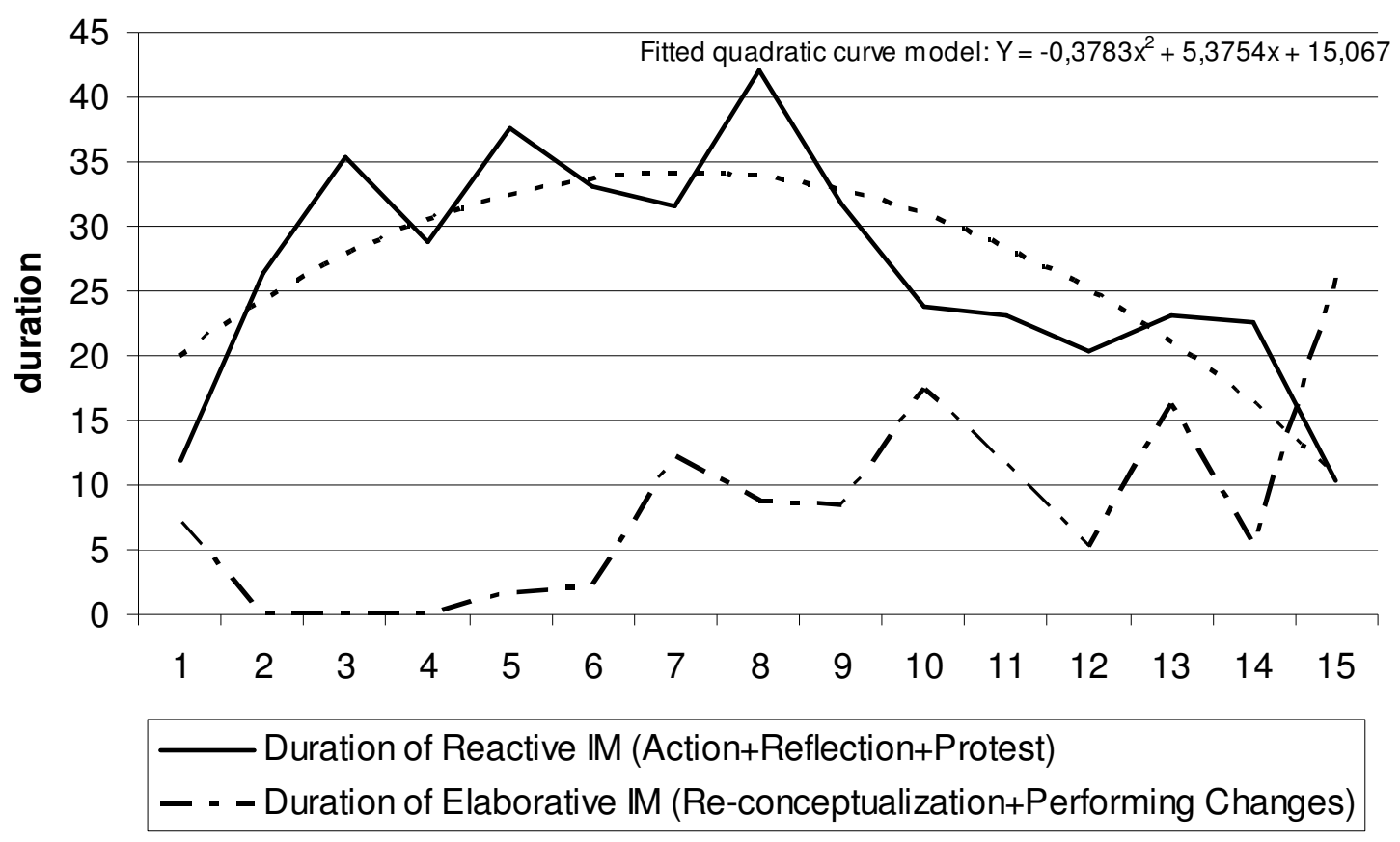

Figure 2. Quadratic curve of Rective i-moments duration and curve about Elaborative i-moments duration.

The Table 1 reports the coefficients of correlation (Spearman's Rho) between the SN and the two indexes derived by IMCS, for the two stages of the psychotherapy. The SN correlates significantly with the reactive imoments both in the first and in the second stage (first stage: Rho = $.639 ;$ p. $=.032 ;$ second stage: Rho $=-.754 ;$ p. $=.043)$. In the first stage the correlation between SN and the elaborative i-moments is close 0; in the second stage is quite high, though only trendily significant ( $R$ ho $=$ $.522 ;$ p. $=.104)$.

Table 1. Spearman's Rho correlation between SN and duration of reactive i-moments and $\mathrm{SN}$ and elaborative i-moments into the two stages of the psychotherapy.

\begin{tabular}{lcc}
\hline & $\begin{array}{c}\text { First stage } \\
\text { (sessions 1-9) }\end{array}$ & $\begin{array}{c}\text { Second stage } \\
\text { (sessions 10-15) }\end{array}$ \\
\cline { 2 - 3 } SN vs Reactive i-moments & $-.639^{*}$ & $-.754^{*}$ \\
SN vs Elaborative i-moments & -.008 & .522 \\
\hline
\end{tabular}

\footnotetext{
* Correlation is significant at the .05 level (1-tailed).
} 


\section{Discussion}

Preliminarily, it is worth noting that SN as well as the duration of the reactive $\mathrm{i}$-moments and of the elaborative $\mathrm{i}$-moments show trend that are consistent with the theoretical models that informs the methods providing those indexes (respectively the TSSM and the narratological model of the psychotherapy). Previous studies have been devoted to the analysis of these trends (Salvatore, 2010; Gonçalves, 2010), therefore we do not address this topic here. We just refer to them in a general fashion because they support the reliability of the conceptual significance of the indexes our analysis is based on.

Coming on the focus of our study, results are quite consistent with the hypothesis. The significant anticorrelation between SN and the reactive $i$-moments in both stages was what expected by the hypothesis 1 and hypothesis 3. Moreover, also the trend of the associations between these two indexes are those hypothesised: in the first stage the associations reflect the decreasing of SN and the contextual increasing of the reactive $\mathrm{i}$-moments (as stated by the hypothesis 1); the inverse happens in the second stage (as stated by the hypothesis 3). Also the correlation between $\mathrm{SN}$ and the elaborative i-moments is consistent with the hypothesis, even if not fully. Consistently with our expectation, we have find no correlation between SN and duration of elaborative imoments in the first stage, while we have found a quite high positive correlation between the two indexes, as expected by the hypothesis 2 . One could observe that this correlation is only trendily significant. Nevertheless, we are led to consider it meaningful, given the very low power of the analysis due to the limited number of cases $(n=6)$.

Taking these results as a whole, they lead to conclude that - at least in the Lisa's psychotherapy - the weakening of the initial patient's assumptions have created the room for the emergence of innovative meanings challenging the dominant narrative. After and thanks to this first phase, that has lasted two third of the therapy, Lisa has had the 
opportunities to elaborate new super-ordered meanings, and with them to develop and consolidate new narratives, reflecting projectual and reflexive competences acquired within and through the clinical work.

\section{Conclusion}

This study has been aimed at deepening the relationship between the formal and functional - in last analysis: abstract - description of the dynamics of sense-making sustaining the psychotherapy process provided by DFA and the contents of the narrative that such dynamics produces. The conceptual framework of the DFA (the TSSM) is based on the idea of a systematic connection between these two levels of sensemaking and then of the psychotherapy process. Such a connection does not concern the specific content of the clinical exchange - that is it is not assumed that a give level/mode of functioning of the Discourse Network correspond to a certain set of content. Rather, the connection is laid at the level of the clinical value of the content of the narrative: the clinical relevance of the DFA requires that the formal and functional aspects of the sense-making that this method allows to grasp are systematically associated with the clinical value of what the patient thinks and feels, then says in session - namely, the content if her/his narrative.

The study we have reported in this paper has provided evidence supporting this assumption. It as analyzed the association between the main DFA index (SN) - which is an index concerning a functional level of analysis (namely the regulative function of some hierarchically superordered meaning, as defined by exclusively formal criteria), fully unconnected with the level of the content - and two indexes derived by the IMCS - which is a method of analysis focused on the content of the narrative, interpreted in the terms of their clinical value (as therapeutically relevant moment of change). The findings of this analysis support the DFA definition of this index: the association 
between the SN and the i-moments through the psychotherapy course leads to conclude that $\mathrm{SN}$ is a valid way of measuring the incidence of the super-ordered meanings regulating the patient's narrative. Indeed, assuming the validity of this index enables to draw a meaningful picture of Lisa case: the patient produces innovation in her narratives consistently with the fact that her super-ordered system of assumptions is before weakened (deconstructive stage) and then developed in new ways (constructive stage). More in general, the findings provided by the study support the basic idea that the formal and functional level of description of the psychotherapy process has clinical relevance because it is connected with the clinical value of the content of patient's narrative.

This evidence is hearting, but obviously all but definitive. Our study suffers of not marginal limitations. First of all, it is focused just on a case. Therefore, the results it provides require to be further tested on other cases, including negative outcome cases as well as cases reflecting other kinds of therapeutic orientation. Secondly, the splitting of the sessions in order to articulate the psychotherapy in two stages has not been made accordingly to an independent clinical criterion, as in accordance with the model that the study is aimed at validating. A third issue concerns the limited number of cases, compromising the statistical power of the analysis.

These limitations (that we are addressing by further studies by now in course) suggest prudence. Nevertheless, they do not obscure the relevance of the methodological and theoretical goal this study has intended to address. Connecting the formal and functional description of the sense-making provided by DFA and the IMCS clinical interpretation of the content of the patient's narrative is a methodological operation that goes beyond the DFA. The elaboration of abstract models of the clinical phenomena is a lever for the development of the field. As other scientific domains show, the commitment on 
abstract models empowers the capacity of generalization and of connection among phenomena empirically distanced (Gennaro et al., 2010). Abstraction allows the elaboration of a shared language within the clinical domain and between the clinical domain and other areas of the psychology and social science. The opportunities entailed in such perspective are evident at the level of theory, of clinical practice as well as training. Nevertheless, progress in this direction is possible only at the condition that the abstraction does not mean lack of clinical significance. Therefore we need not only formalization of models, but also clinical analysis and empirical studies anchoring the theoretical elaboration to the clinical experience.

\section{References}

Angus, L., Goldman, R., \& Mergenthaler, E. (2008). Introduction. One case, multiple measures: An intensive case-analytic approach to understanding client change processes in evidence-based, emotion-focused therapy of depression. Psychotherapy Research, 18(6), 629-633.

Austin, J. (1962). How to do Things with Words. Oxford: Oxford University Press.

Bakeman, R., \& Gottman J.M. (1997). Observing interaction. An introduction to sequential analysis ( $2_{\text {nd }}$ ed.). Cambridge: Cambridge University Press.

Beck, A.T., Ward, C.H., Mendelson, M., Mock, J., \& Erbaugh, J. (1961). An inventory for measuring depression. Archives of General Psychiatry, 4, 561571.

Benzécri, J.P. (1973). L'Analyse des Données, Tome I: La Taxinomie, Tome II: Correspondances. Paris: Dunod.

Bolasco, S. (1999). Analisi multidimensionale di dati [Multidimensional data analysis]. Roma: Carocci.

Borckardt, J.J., Mash, M., Murphy, M.D., Moore, M., Shaw, D., \& O'Neil, P. (2007). Clinical Practice as Natural Laboratory for Psychotherapy Research. A Guide to Case Based Time-Series Analysis American Psychologist 63(2), 77-95.

Chambers, J., \& Bickhard, M. (2007). Culture, Self and Identity.Interactivist Contributions to a Metatheory for Cultural Psychology. Culture \& Psychology, 13(3), 259-295.

Cole, M. (1996). Cultural Psychology. A once and future discipline. Cambridge Mass.: Harvard University Press.

Derogatis, L.R., Rickels, K., \& Roch, A.F. (1976). The SCL-90 and the MMPI: A step in the validation of a new self-report scale. British Journal of Psychiatry, 128, 280-289. 
Dimaggio, G., \& Semerari, A. (2004). Disorganized narratives: The psychological condition and its treatment. In L. Angus \& J. McLeod (Eds.), The Handbook of Narrative and Psychotherapy. Practice, Theory and Research (pp. 263-282). Thousand Oaks, CA: Sage.

Dimaggio, G., Semerari, A., Carcione, A., Nicolò, G., \& Procacci, M. (2007). Psychotherapy of Personality Disorder: Metacognition, States of Mind and Interpersonal Cycles. London, Routledge.

Edwards, D., \& Potter, J. (1992). Discursive Psychology. London: Sage.

Elliott, R., \& Anderson, C. (1994). Simplicity and complexity in psychotherapy research. In R.L. Russell (Ed.), Reassessing psychotherapy research (pp. 65-113). New York: Guilford Press.

Freda, M.F. (2008) Understanding narrative role in depicting meaning and clinical intervention. In S. Salvatore, J. Valsiner, S. Strout-Yagodzynski \& J. Clegg (Eds.), Yearbook of Idiographic Science - Volume 1 (pp. 81-94). Rome: Firera \& Liuzzo Group.

Freedman, J., \& Combs, G. (1996). Narrative therapy: The social construction of preferred realities. New York: Norton.

Gennaro, A., Al-Radaideh, A., Gelo, O., Manzo, S., Nitti, M., Auletta, A.., \& Salvatore, S. (2010). Modelling the psychotherapy process as a meaningmaking dynamics. The Two Stage Semiotic Model (TSSM) and the Discourse Flow Analyzer (DFA). In S. Salvatore, J. Valsiner, J. Travers Simon \& A. Gennaro (Eds.), YIS: Yearbook of Idiographic Science 2009 Volume 2 (pp. 131-170) Roma: Firera Publishing Group.

Gergen, K.J. (1999). An invitation to Social Construction. London: Sage.

Gonçalves, M.M., Matos, M., \& Santos, A. (2008). Innovative moments coding system. Version 7.0. Braga, Portugal: University of Minho (Available from the authors).

Gonçalves, M.M., Matos, M., \& Santos, A. (2009). Narrative therapy and the nature of "innovative moments" in the construction of change. Journal of Constructivist Psychology, 22, 1-23.

Gonçalves, M.M., Ribeiro, A., Matos, M., Santos, A., \& Mendes, I. (2010). The Innovative Moments Coding System: A new coding procedure for tracking changes in psychotherapy. In S. Salvatore, J. Valsiner, J. Travers Simon \& A. Gennaro (Eds.), YIS: Yearbook of Idiographic Science 2009 - Volume 2. Rome: Firera Publishing Group.

Greenberg, L.E. (1994). The investigation of change: Its measurement and explanation. In R.L. Russel (Ed.), Reassessing psychotherapy research (pp. 114-143). New York/London: Guilford Press.

Greenberg, L.S., \& Pinsof, W.M. (Eds.). (1986). The psychotherapeutic process: A research handbook. New York: Guilford Press.

Greenberg, L.S., \& Pinsoff, W.M.(Eds.) (1986). The psychotherapeuthic process: A research handbook. New York Guildford Press

Harré, R., \& Gillett, G. (1994). The Discursive Mind. London: Sage Publication.

Hayes, A.M., \& Strauss, J. (1998). Dynamic systems theory as a paradigm for the study of change in psychotherapy: An application to cognitive therapy for depression. Journal of Consulting and Clinical Psychology, 66(6), 939947.

Hermans, H.J.M., \& Hermans-Jansen, E. (1995). Self-narratives. The construction of meaning in psychotherapy. New York: Guilford Press.

Hoffman, I.Z. (1998). Ritual and Spontaneity in the Psychoanalytic Process. New Jersey Hillsdale: The Analytic Press Inc. 
Research in Psychotherapy 2011; 14(1): 90-120

http://www.researchinpsychotherapy.net

Horowitz, L.M., Rosenberg, S.E., Baer, B.A., Ureno, G., \& Villasenor, V.S. (1988). Inventory of Interpersonal Problems: Psychometric properties and clinical application. Journal of Consulting and Clinical Psychology, 56, 885892.

Horvath, A., \& Greenberg, L.S. (1989). Development and validation of the Working Alliance Inventory. Journal of Counseling Psychology, 36, 223-233.

Kossmann, M.R., \& Bullrich, S. (1997). Systematic chaos: Self-organizing systems and the process of change. In F. Masterpasqua \& P.A. Perna (Eds.), The psychological meaning of chaos: Translating theory into practice. (pp. 199-224). Washington, DC: American Psychological Association.

Kowalik, Z.J., Schiepek, G., Kumpf, K., Roberts, L., \& Elbert, T. (1997). Psychotherapy as a chaotic process II: The application of nonlinear analysis methods on quasi time series of the client-therapist interaction: A non stationary approach. Psychotherapy Research, 7(3), 197-218.

Lancia, F. (2002). The Logic of a Textscope. Retrivied August 18, 2007 from http://www.tlab.it/en/bibliography.php.

Lancia, F. (2004). Strumenti per l'analisi dei testi. Introduzione all'uso di T-LAB [Tools for textual analysis. An introduction to T-LAB]. Milano: Franco Angeli.

Lauro-Grotto, R.P., Salvatore, S., Gennaro, A., \& Gelo, O. (2009). The unbearable dynamicity of psychological processes: Highlights of the psychodynamic theories. In J. Valsiner, P. Molenaar, M. Lyra, \& Nandita Chaudhary (Eds.), Dynamics Process Methodology in the Social and Developmental Sciences (pp.1-30) New York: Springer.

Linell, P. (2009). Rethinking Language, Mind, and World Dialogically. Charlotte, NC: Information Age publishing.

Mahoney, M.J., \& Marquis, A. (2002). Integral constructivism and dynamic systems in psychotherapy processes. Psychoanalitic Inquiry, 22, 794-813.

Matos, M., Santos, A., Gonçalves, M., \& Martins, C. (2009). Innovative moments and change in narrative therapy. Psychotherapy Research, 19(1), 68-80.

Nightgale, D.J. \& Cromby, J. (Eds.). (1999). Social constructionist psychology. A critical analysus of theory and practice. Buckingham: Open University Press.

Nitti, M., Ciavolino, E., Salvatore, S.,Gennaro, A. (2010). Analyzing psychotherapy process as intersubjective sensemaking. An approach based on discourse analysis and neural networks. Psychotherapy Research 29(5), 546-563

Rosemberg, S.D., Schnurr, P.P., \& Oxman, T.E. (1990). Content Analysis: A Comparison of Manual and Computerized Systems. Journal of Personality Assessment, 5(1 \& 2) , 298-310.

Russell, R.L. (1994). Reassessing psychotherapy research. New York: Guilford Press.

Salvatore, S., Gelo, O., Gennaro, A., Manzo, S., \& Al-Radaideh, A. (2010). Looking at psychotherapy as an intersubjective dynamic of sensemaking. A case study with Discourse Flow Analysis. Journal of Constructivist Psychology, 23(3), 195-230.

Salvatore, S., Gennaro, A., Auletta, A, Al-Radaideh, A. A. M., Aloia, N., Masiello, F., Monteforte, G., Tonti, M., Manzo, S., \& Gelo, O. (2010, June). Prespectives for the textual data analysis: A contextual approach. Paper presented at the $41^{\text {st }}$ SPR-International Meeting, Asilomar, California. 
Salvatore, S., Gennaro, A., Grassi, R., Manzo, S., Melgiovanni, S., Mossi, P., Olive, C., \& Serio, A.V. (2007). La dinamica discorsiva dello scambio terapeutico come indice clinico. Applicazione del DFA (Discursive Flow Analyzer) alla psicoterapia di Katja [The study of the therapeutic process in terms of the discourse dynamic. The application of DFA (Discourse Flow Analyzer) to case K.] (pp. 355-397). In G. Nicolò \& S. Salvatore (Eds.), La ricerca sui risultati e sul processo in psicoterapia. Roma: Edizioni Carlo Amore.

Salvatore, S., Lauro-Grotto, R., Gennaro, A., \& Gelo, O. (2009). Grasping the dynamic nature of intersubjectivity. In J. Valsiner, P. Molenaar, M. Lyra, \& H. Chaudary (Eds.), Dynamics process methodology in the social and developmental sciences (pp. 171-190). New York: Springer.

Salvatore, S., Tebaldi, C., \& Poti, S. (2006/2009). The discorsive dynamic of sensemaking. In S. Salvatore, J. Valsiner, S. Strout-Yagodzynski, J. Clegg (Eds.) YIS: Yearbook of Idiographic Science - Volume 1 (pp. 39-71).

Salvatore, S., Tebaldi, C., \& Poti, S. (2009). The discursive dynamic of sensemaking. In S. Salvatore, J. Valsiner, S. Strout \& J. Clegg (Eds.), YIS: Yearbook of Idiographic Science 2008 - Volume 1 (pp. 39-72). Rome: Firera Publishing. First published 2006, in International Journal of Idiographic Science [On Line Journal], Article 3. Retrieved (September 20, 2008) from http://www.valsiner.com/articles/salvatore.htm.

Salvatore, S., \& Valsiner, J. (2006). 'Am I really a Psychologist?'. Making sense of a super-human social role. European Journal of School Psychology, 4(2), 5-30

Samoilov, A., \& Goldfried, M.R. (2000). Role of emotion in cognitive-behavior therapy. Clinical Psychology: Science and Practice, 7, 373-385.

Santos, A, Gonçalves, M., Matos M., \& Salvatore, S. (2009). Innovative moments and change pathways: A good outcome case of narrative therapy. Psychology and Psychotherapy: Theory, Research and Practice, 82, 449446.

Santos, A., \& Gonçalves, M.M. (2009). Innovative moments and change processes in psychotherapy: An exercise in a new methodology. In $\mathrm{J}$. Valsiner, M. Lyra \& P. Molenaar (Eds.), Handbook of dynamic process methodology in the social and developmental sciences (pp. 493-526). New York: Springer.

Schiepek, G., Kowalik, Z.J., Schiitz, A., Kohler, M., Richter, K., Strunk, G., Miihlnickel, W., \& Elbert, T. (1997). Psychotherapy as a chaotic process I: Coding the client-therapist interaction by means of a sequential plan and the search for chaos: A stationary approach. Psychotherapy Research, 7(2), 173-194.

Stiles, W.B. (2006). Assimilation and the process of outcome: Introduction to a special section. Psychotherapy Research, 16(4), 389-392.

Storolow, R.D., Atwood, G.E., \& Brandchaft, B. (1994). The intersubjective perspective. Hillsdale, NJ: Jason Arason.

Teasdale, J.D., \& Barnard, P.J. (1993). Affect, cognition, and change: Remodeling depressive thought. Hillsdale, NJ: Erlbaum.

Tschacher, W., Baur, N., \& Grawe, K. (2000). Temporal interaction of process variables in psychotherapy. Psychotherapy Research, 10(3), 296-309.

Tschacher, W., Schiepek, G., \& Brunner, E.J. (Eds.). (1992). Self-organization and clinical psychology. Berlin: Springer. 
Research in Psychotherapy 2011; 14(1): 90-120

http://www.researchinpsychotherapy.net

Valsiner, J., \& Van der Veer, R. (2000). The social mind. Cambridge: University Press.

Valsiner, J., Molenaar, P.C.M., Lyra, M.C.D.P., \& Nandita, C. (2009). Dynamic

Process Methodology in the Social and Developmental Sciences. New York: Springer Verlag.

White, M. (2007). Maps of narrative practice. New York: Norton.

Wittgenstein, L. (1953). Philosophische Untersuchungen (engl. trans. Philosophical Investigations, 2nd ed.) Oxford: Basil Blackwell. 